See Article page 578.

\section{Commentary: Robotic repair of diaphragmatic hernia}

\author{
Benny Weksler, MBA, MD
}

Repair of traumatic diaphragmatic hernias can be complex. ${ }^{1}$ Traditionally, surgeons fixed these hernias either through an open thoracotomy or via the abdomen with laparoscopy. Often, intrathoracic adhesions make the repair from the abdomen difficult. Very large diaphragmatic hernias occupying most of the chest can also make a transabdominal repair difficult. Finally, reentering the abdominal cavity to repair the hernia in patients with a hostile abdomen may increase the risk of complication and is often avoided.

In the current issue of the JTCVS Techniques, Sideris and Molena $^{2}$ report a case of a patient with a diaphragmatic hernia after debulking for ovarian cancer. Debulking included disease on both hemi-diaphragms. In the late postoperative period (6 months), she was found to have a large hernia through the left hemidiaphragm containing stomach. The authors used the DaVinci robot to repair the diaphragm. The authors used primary repair reinforced with absorbable mesh, in a "sandwich" fashion, with mesh on both the thoracic and abdominal side of the diaphragm after taking down adhesions in the abdominal side. I would encourage the reader to watch the excellent video submitted with the manuscript, in which the authors demonstrate their technique. The patient did well and was discharged home on postoperative day 1 .

The surgical robot is a versatile tool that can facilitate some complex procedures. The mobility inside a tight cavity and wrist articulation makes suturing relatively easy. The ease of suturing facilitates the repair of a diaphragmatic hernia. I like the authors' option for a transthoracic

\footnotetext{
From the Division of Thoracic and Esophageal Surgery, Department of Thoracic and Cardiovascular Surgery, Allegheny General Hospital, Pittsburgh, Pa.

Disclosures: Dr Weksler reported proctor for Intuitive Surgery and speaker for AstraZeneca.

The Journal policy requires editors and reviewers to disclose conflicts of interest and to decline handling or reviewing manuscripts for which they may have a conflict of interest. The editors and reviewers of this article have no conflicts of interest.

Received for publication Sept 9, 2021; revisions received Sept 9, 2021; accepted for publication Sept 10, 2021; available ahead of print Sept 16, 2021.

Address for reprints: Benny Weksler, MBA, MD, Department of Thoracic and Cardiovascular Surgery, Drexel University College of Medicine, Allegheny General Hospital, 320 E North Ave, 14th Fl, South Tower, Pittsburgh, PA 15212 (E-mail: benny.weksler@ahn.org).

JTCVS Techniques 2021;10:581

2666-2507

Copyright (c) 2021 The Author(s). Published by Elsevier Inc. on behalf of The American Association for Thoracic Surgery. This is an open access article under the CC BY-NC-ND license (http://creativecommons.org/licenses/by-nc-nd/4.0/).

https://doi.org/10.1016/j.xjtc.2021.09.024
}

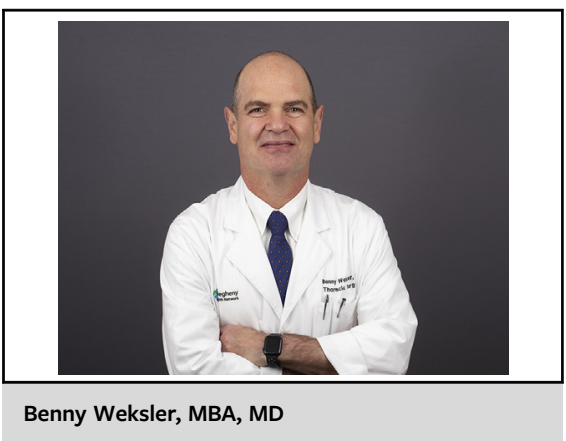

CENTRAL MESSAGE

Robotic transthoracic repair of diaphragmatic hernias is an option in the face of a hostile abdomen.

approach. With a hostile abdomen, just the laparoscopic entry may induce serious complications. Many will question the use of absorbable mesh on both sides of the diaphragm, and others may question the use of mesh altogether. However, there are no clear guidelines on the use of mesh in this patient population. If one borrows from other types of chronic hernias, such as ventral hernias, the use of mesh was shown to be beneficial in decreasing recurrences. ${ }^{3}$ Although I do not use mesh routinely, the case presented by Sideris and Molena may be a time in which I would consider using an absorbable mesh to make up for the previous debulking and stripping. With a lack of Level I evidence, we must use our clinical judgment in this type of situation.

\section{References}

1. Blitz M, Louie BE. Chronic traumatic diaphragmatic hernia. Thorac Surg Clin 2009; 19:491-500.

2. Sideris AC, Molena D. Robotic transthoracic diaphragmatic hernia repair. $J$ Thorac Cardiovasc Surg Tech. 2021;10:578-80.

3. Holihan JL, Hannon C, Goodenough C, Flores-Gonzalez JR, Itani KM Olavarria O, et al. Ventral hernia repair: a meta-analysis of randomized controlled trials. Surg Infect (Larchmt). 2017;18:647-58. 